MATEC Web of Conferences 19, 01006 (2014)

DOI: $10.1051 /$ matecconf/ 20141901006

C) Owned by the authors, published by EDP Sciences, 2014

\title{
Investigation of water and saline solution drops evaporation on a solid substrate
}

\author{
Evgenija G. Orlova ${ }^{a}$, Geniy V. Kuznetsov \\ National Research Tomsk Polytechnic University, 634050 Tomsk, Russia
}

\begin{abstract}
Experimental investigation water and saline solution drops evaporation on a solid substrate made of anodized aluminum is presented in the paper. Parameters characterizing drop profile have been obtained (contact angle, contact diameter, height). The specific evaporation rate has been calculated from obtained values. It was found that water and saline solution drops with concentration up to $9.1 \%$ evaporate in the pinning mode. However, with increasing the salt concentration in the solution up to $16.7 \%$ spreading mode was observed. Two stages of drop evaporation depending on change of the evaporation rate have been separated.
\end{abstract}

\section{Introduction}

Heat and mass transfer of evaporating liquid drop on a solid substrate is the most advanced direction of heat technology modernization in constructing of high-heat exchange systems, in the chemical industry for drying liquid dispersions (pneumatic, spray, rotary, drum, spiral dryer) [1], in aviation at solving "the problem of freezing aircrafts", in the mechanical engineering at designing heat engines, in medicine at the study of microstructures of DNA / RNA [2] and etc.

The purpose of present work is the experimental investigation of effect of saline solution initial concentration on change of specific evaporation rate, contact diameter and contact angle at drop evaporation on a solid heated substrate. We also compared the changes in the characteristics of the wetting and spreading of aqueous salt solutions with distilled water droplets.

\section{Research technique}

The researches have been conducted using experimental setup shown in Fig.1. It consists of shadow and Schlieren systems [3].

The high-speed camera Fastvideo-500M was used in each system. Recording was carried out with 10 frames per second and with a resolution of $1280 \times 1024$ pixels. The heat of the substrate made of anodized aluminum (Fig. 2) was realized with a Peltier element (thermoelectric transducer type A2TM 8.0-127/126-1.4 HR1).

\footnotetext{
${ }^{a}$ Corresponding author: enja199105@gmail.com
} 


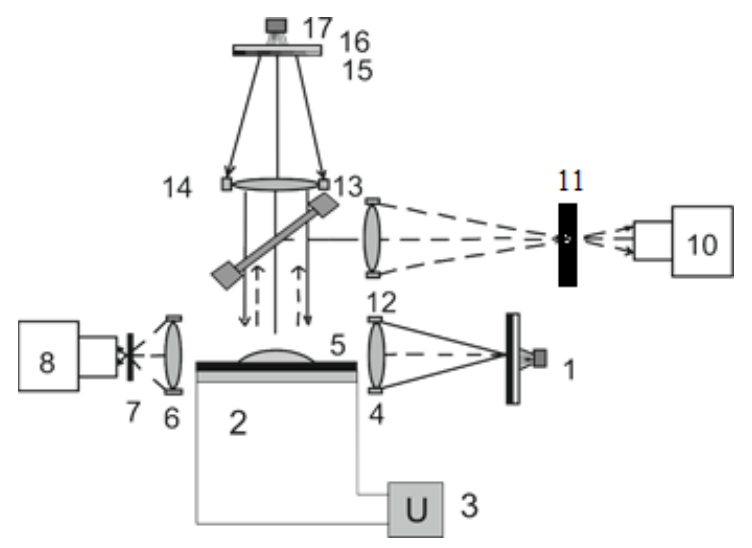

Figure 1. Schematic diagram of the experimental setup: 1, 17 - light source; 2 - Peltier element; 3 - power source; 4, 14 - collimating lens; 5- substrate; 6 - condensing lens; 7, 11 - transparent shield with a hole; 8,10 high-speed video cameras; 12 - Schlieren lens; 13 - beam splitter; 15, 16 - coding filter.

The substrate profile was studied using surface analyzer "Micro Measure 3D station".

Measuring of the temperature of the substrate was performed by eight-channel Agilent 34901A. Three thermocouples "chromel-copel" with measurement error $\pm 0.1^{\circ} \mathrm{C}$ were used as the temperature sensors. When substrate temperature is achieved of $61{ }^{\circ} \mathrm{C}$ drop of a predetermined volume placed on the substrate using a syringe dispenser. Then a drop has been heated and vaporized.

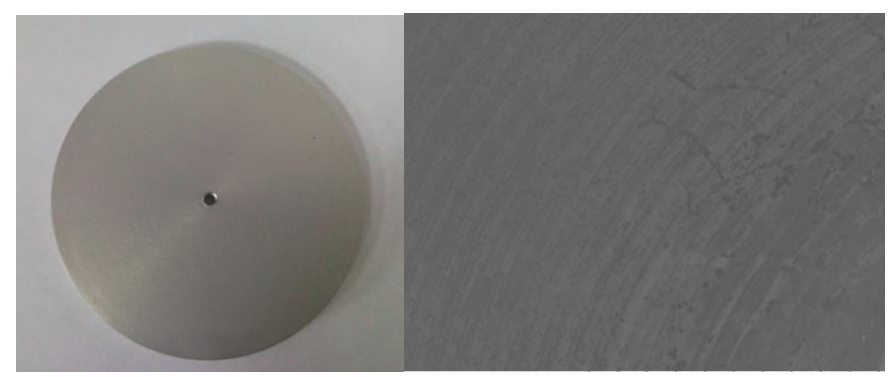

a

b

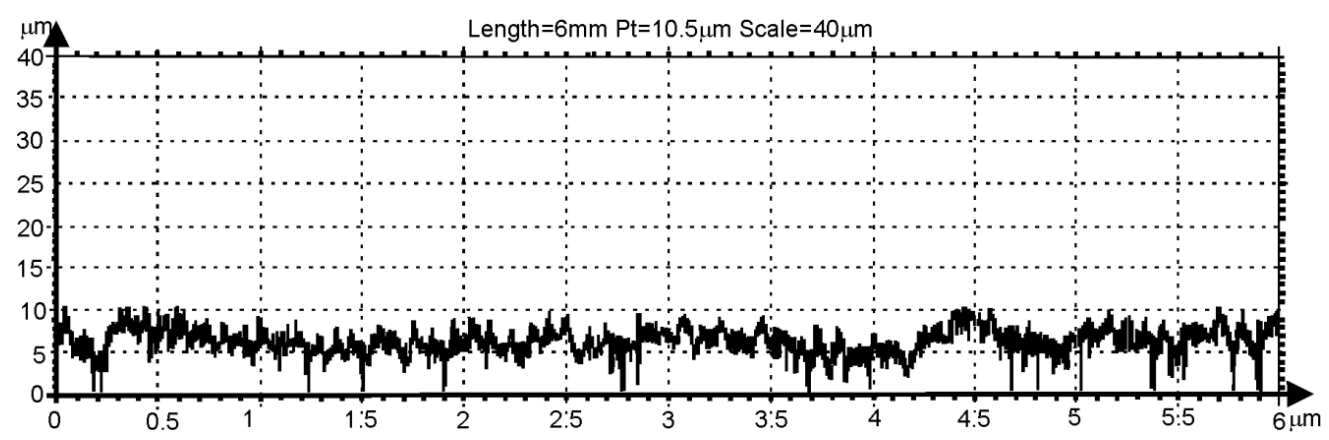

c

Figure 2. The substrate made of anodized aluminum: a) Magnification: x1; b) Magnification: x100; c) Profile of a substrate.

According to results of the preliminary experiment, the values of influencing factors were defined (Table 1). 
The $2^{\text {nd }}$ International Youth Forum "Smart Grids"

Table 1. Main influencing factors.

\begin{tabular}{|c|c|}
\hline Drop volume & $60 \mu \mathrm{l}$ \\
\hline Substrate material & anodized aluminum \\
\hline $\begin{array}{c}\text { Roughness parameter of surface } \\
\text { (Ra) }\end{array}$ & $0,971 \mu \mathrm{m}$ \\
\hline Wetting liquid & non deaerate distilled water, $, 1 \%, 16.7 \%$ \\
\hline Temperature on the substrate & $61{ }^{\circ} \mathrm{C}$ \\
\hline Temperature under the substrate & $62.5^{\circ} \mathrm{C}$ \\
\hline
\end{tabular}

Recording of the experimental data (contact angle, contact radius, height) was carried out with using KRUSS program [4]. The snapshots obtained during the experiment were processed by the program. The initial values of the curves plotted from the experimental data correspond to the time of placing a drop on the substrate. Recording of the investigated parameters was performed before formation of salt rings in the final stages of evaporation.

\section{Results and discussion}

The specific evaporation rate was determined by the following equation [5]:

$$
E S=\frac{\left(V_{i}-V_{i+1}\right)}{\Delta t \cdot\left(A_{i}+A_{i+1}\right) / 2}, \frac{m l}{s \cdot m m^{2}}
$$

Where $V_{i}, A_{i}, V_{i+1}, A_{i+1}$ - are the volume and surface area of the droplet at the time $\mathrm{t}$ and $t_{i+1}$.

Contact angle of evaporating drop on anodized aluminum is plotted in Fig.3.

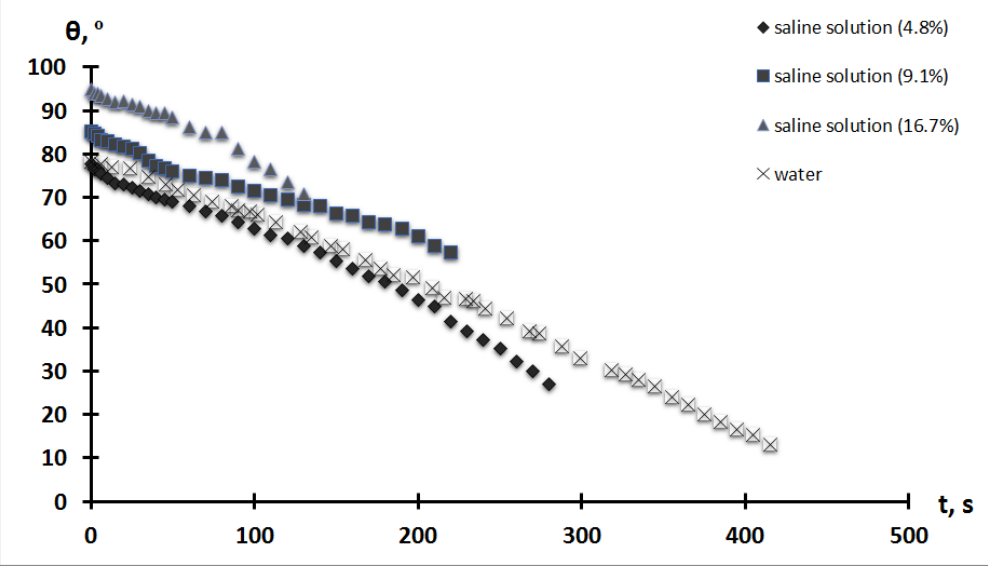

Figure 3. Contact angle of evaporating drop $(\mathrm{V}=60 \mu \mathrm{l} ; \mathrm{c}=4.8 \% ; 9.1 \% ; 16.7 \%)$ on substrate made of anodized aluminum.

It was found that during the evaporation of water and saline solution drops contact angle decreases linearly. Similar results were obtained during experimental studies on substrates of spin-Teflon, spray Teflon and aluminum heated to $64^{\circ} \mathrm{C}$, volume of distilled water drops were varied from $88,7 \mu 1$ to $104,7 \mu 1[5]$.

Water drop on anodized aluminum evaporates in the pinning mode with constant wetting area (Fig.4). Saline solution drops with concentration of $4.8 \%$ and $9.1 \%$ have the same evaporation mode. 


\section{MATEC Web of Conferences}

But with increasing concentration up to $16.7 \%$ contact diameter increases. Three-phase contact line is moving in the direction of increasing the area occupied by the drop (spreading mode).

With increasing salt concentration in the solution the surface tension of the droplet slightly increases, that prevents drop spreading on the substrate, i.e. at the initial time of the evaporation process drops with a higher concentration $(16.7 \%)$ have minimal contact diameter $(6.580 \mathrm{~mm})$, and vice versa, pure liquid (water) drop has the diameter of $8.064 \mathrm{~mm}$.

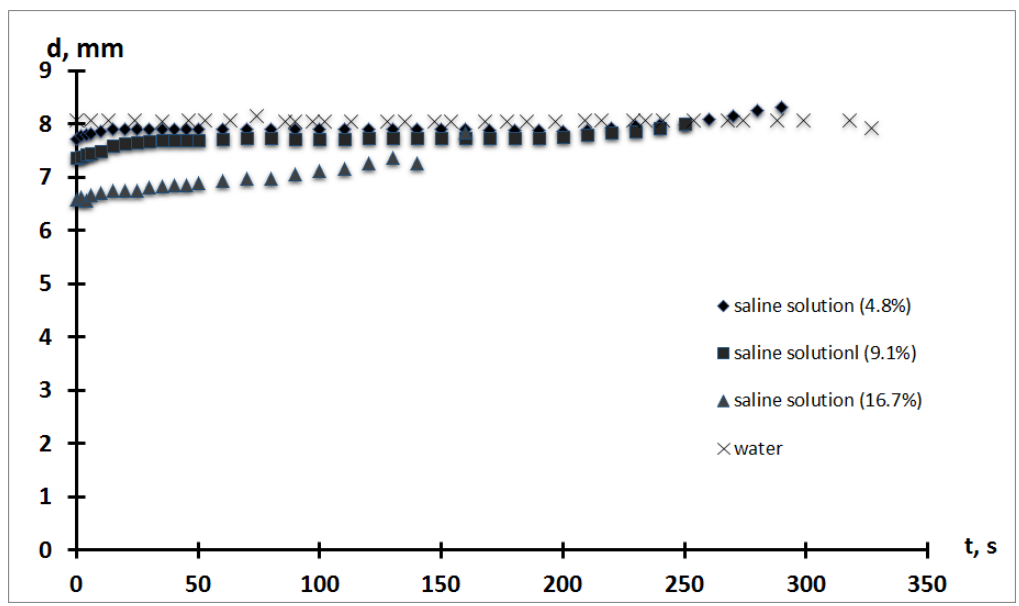

Figure 4. Contact diameter of evaporating drop $(\mathrm{V}=60 \mu \mathrm{l} ; \mathrm{c}=4.8 \% ; 9.1 \% ; 16.7 \%)$ on substrate made of anodized aluminum.

Drop profile evolution in pinning and spreading evaporation mode is shown in Fig. 5.

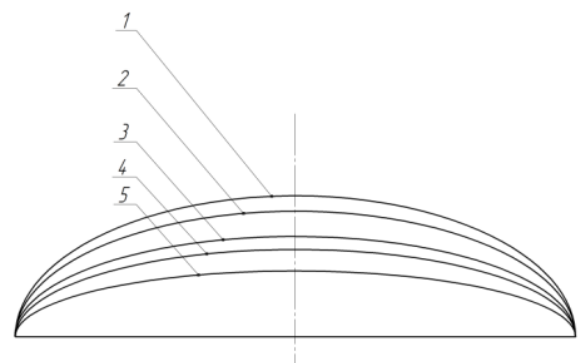

(a)

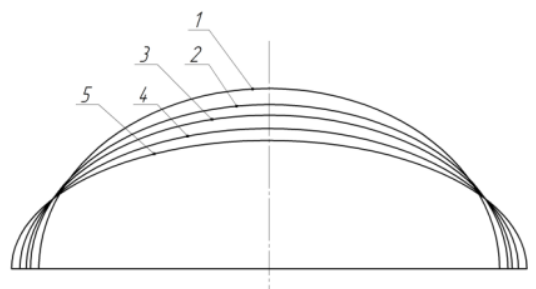

(b)

Fig.5. Drop profile evolution in: (a) - pinning mode at time of evaporation 0.1 (1), 35 (2), 120 (3), 200 (4), 280 c (5); (b) - spreading mode at time of evaporation 0.1 (1), 30 (2), 60 (3), 100 (4), $130 \mathrm{c} \mathrm{(5).}$

The calculated specific evaporation rate of drops on the anodized aluminum is plotted in Fig.6. Two stages of drop evaporation depending on change in the evaporation rate have been separated. First stage is characterized by a slight change in the evaporation rate $(8-10 \%)$ for water droplets and saline solution. Next there is a sharp increasing in the specific evaporation rate of water drop (from $0.0026 \mu \mathrm{l} /\left(\mathrm{s} \cdot \mathrm{mm}^{2}\right)$ to $\left.0.0062 \mu \mathrm{l} /\left(\mathrm{s} \cdot \mathrm{mm}^{2}\right)\right)$. Second stage of evaporation is absent for saline solution drops. It happens because at the end of the first mode there is a formation of salt crystals and the solvent is completely evaporated. 


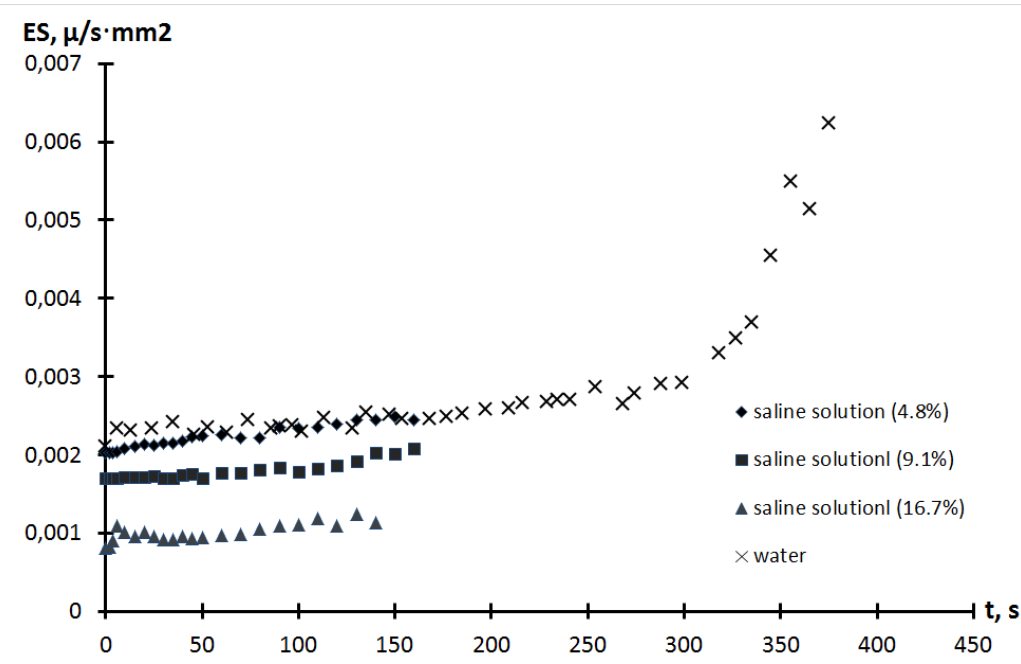

Fig. 6. Specific evaporation rate of water and saline solution drop (V=60 $\mu 1 ; c=4.8 \% ; 9.1 \% ; 16.7 \%)$ on substrate made of anodized aluminum.

\section{Conclusion}

It has been found that water and saline solution drops $(4.8 \%$ and $9.1 \%)$ evaporate in pinning mode. But with increasing concentration up to $16.7 \%$ contact diameter increases (spreading mode).

The important result of work is calculation of the specific evaporation rate. Two stages of drop evaporation depending on change in the evaporation rate have been separated. First stage is characterized by a slight change in the evaporation rate for water droplets and saline solution. Next there is a sharp increasing in the specific evaporation rate of water drop. Second stage of evaporation is absent for saline solution drops.

The work was realized within the research state assignment "Science" (Code of Federal Target Scientific and Technical Program 2.1410.2014).

\section{References}

1. Strumillo C. Drying: Principles, Applications and Design. - New York: Gordon and Breach, 1986. $-448 \mathrm{p}$.

2. H. Hu, R.G. Larson, J. Phys. Chem. B. 106, 1334 (2002)

3. E. Orlova, G. Kuznetsov and D. Feoktistov. EPJ Web of Conferences, 76, 012039 (2014).

4. Web site: http://www.kruess.com.

5. E. Ya. Gatapova, A. A. Semenov et al. Colloids Surf., A 441, 776 (2014) 